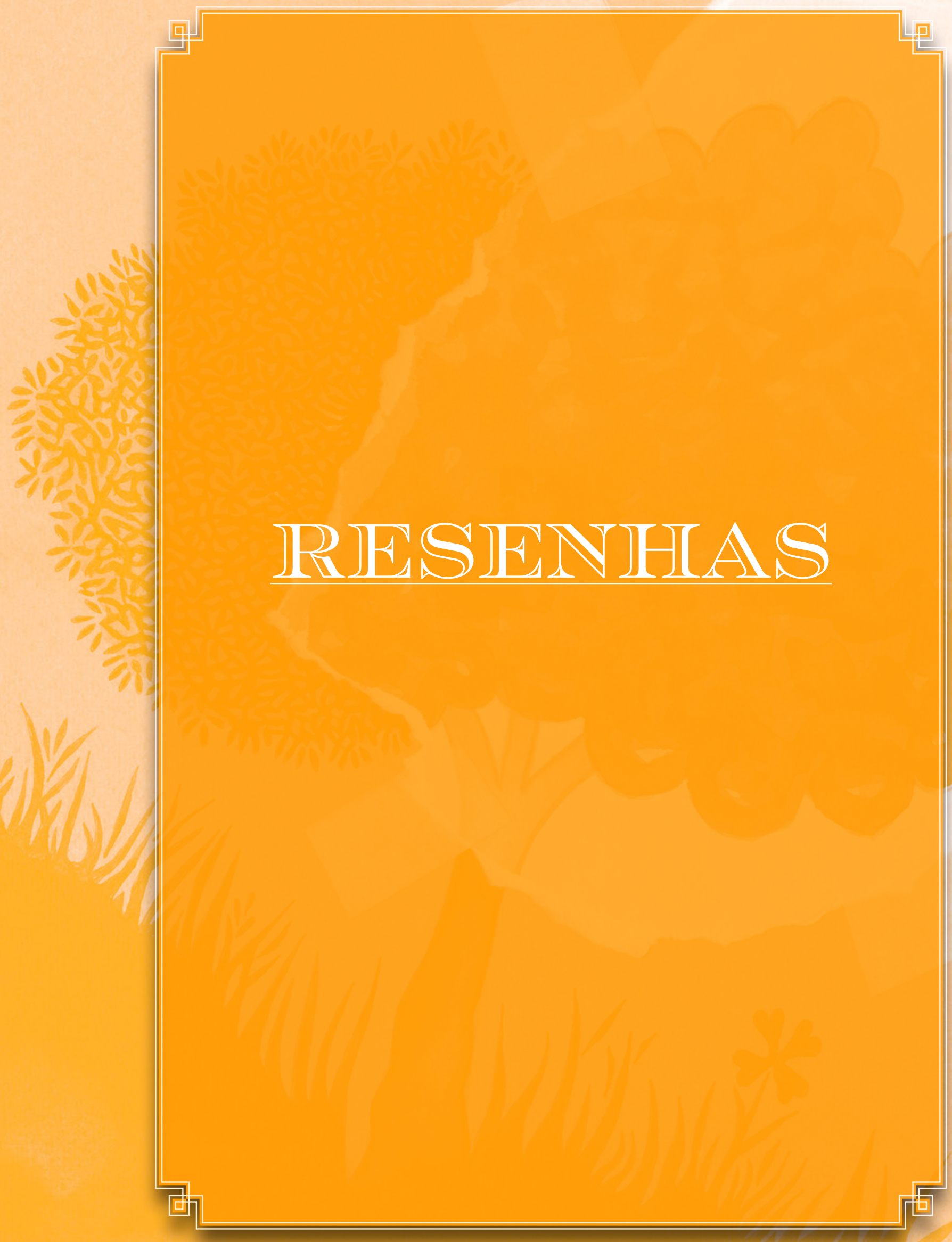




\title{
AUSCHWITZ EXPLICADO À MINHA FILHA
}

\author{
AUSCHWITZ EXPLAINED TO MY CHILD
}

\author{
Luciane Bonace Lopes Fernandes'
}

1 Doutorado em Educação pela Universidade de São Paulo, Brasil. (2015).Pós-doutorado em Metodologia do Ensino e Educação Comparada pela Faculdade de Educação da Universidade de São Paulo (FE-USP) e Pós-doutorado em Letras Orientais pela Faculdade de Filosofia, Letras e Ciências Humanas da Universidade de São Paulo (FFLCH-USP). E-mail: lucianebonace@usp.br 
RESUMO (RESENHA): WIEVIORKA, Annette. Auschwitz explicado à minha filha.

Tradução Maria Beatriz de Medina. São Paulo: Via Lettera Editora, 2000.

ABSTRACT (REVIEW): WIEVIORKA, Annette. Auschwitz explained to my child. Tradução Leah Brumer. Estados Unidos: Da Capo Press, 2002.

PALAVRAS-CHAVE: Auschwitz; Holocausto; Campos de Concentração.

KEYWORDS: Auschwitz; Holocaust; Concentration Camps. 
Auschwitz explicado à minha filha, best seller escrito pela historiadora francesa Annette Wieviorka (1948-), com primeira edição em 1999 pela Éditions du Seuil sob título Auschwitz expliqué à ma fille, foi traduzido para 12 línguas e publicado no Brasil um ano após seu lançamento.

Annette Wieviorka nasceu em Paris, em uma família judia de origem polonesa. Iniciou suas pesquisas sobre a perseguição aos judeus na França e na Polônia durante a Era Nazi na década de 1970 e, desde então, publicou diversos livros sobre o assunto, sendo hoje reconhecida como uma das mais importantes historiadoras do Holocausto. Wieviorka insere o testemunho no centro das pesquisas históricas sobre o Holocausto, estabelecendo uma nova relação da história com o passado e a memória, em que o testemunho se torna o vetor e "o universal reside no mais fragmentário"," sem espaço para verdades universais ou totalizantes. A pesquisadora enfoca também nas memórias das deportações ocorridas na França, coletadas logo após a libertação dos campos de concentração, na opinião pública francesa ao descobrir as atrocidades cometidas nesses campos e de que modo a administração e o exército franceses colaboraram com os sobreviventes no processo de libertação. Wieviorka também coletou testemunhos de sobreviventes franceses e conclui que, imediatamente após o fim da guerra, ninguém estava pronto para ouvi-los. Esses sobreviventes também escreveram diversos livros que não foram lidos. É dela a frase: "A história ideal - irrealizável por ser, ao mesmo tempo, insuportável e longa demais - seria a narração individualizada de seis milhões de mortos". ${ }^{3}$

2 SELIGMANN-SILVA, Márcio O. História, memória e literatura: o testemunho na era das catástrofes. Campinas: Editora UNICAMP, 2003, p. 80.

3 WIEVIORKA, Annette. L'ére du témoin. (The era of witness, 2006). Paris: Plon, 1998. p. 122-123 apud SELIGMANN-SILVA, 2003, p. 80. De acordo com Seligmann-Silva (2003), este livro traça um complexo quadro do testemunho em torno da Shoah. Para o autor, “o estudo das várias ondas de testemunho da Shoah dos primeiros escritos até a fundação dos arquivos de vídeo - e sobretudo a brilhante análise do julgamento, no governo de Ben Gurion, levado a cabo pelo juiz Gidéon Hausner ao modo de um espetáculo testemunhal que praticamente deslanchou a onda de testemunhos incessante e crescente desde então - faz da obra de Wieviorka uma fonte imprescindível para uma reflexão sobre o estatuto do testemunho não apenas dentro da história/memória da Shoah" (2003, p. 80, grifo do autor). 
Auschwitz explicado à minha filha tem a estrutura de uma conversa aberta $\mathrm{e}$ informal entre mãe e filha. Apresenta Introdução e cerca de 80 perguntas objetivas com respostas e explicações detalhadas, numa linguagem direta e sem sentimentalismos. ${ }^{4}$ As informações aparecem de acordo com o interesse e a curiosidade de Mathilde, filha da autora, que lhe dirige uma série de perguntas relacionadas ao desenvolvimento do Nazismo na Alemanha, ao crescimento do antissemitismo na Europa, à perseguição, segregação e extermínio dos judeus, à resistência judaica e à criação de guetos e campos de concentração (não apenas Auschwitz) durante a Segunda Guerra Mundial.

Num primeiro momento, podemos entender a obra como uma produção direcionada aos públicos infantil e juvenil, mas as questões trazidas por Mathilde e respondidas com clareza pela autora também ampliam (e muito!) a visão do público adulto em relação ao genocídio, visto que parte considerável das pessoas, de forma geral, tem como principal fonte de conhecimento do Holocausto a filmografia ${ }^{5}$ produzida entre o final do século XX e o início do século XXI, que explora, por caminhos históricos, estéticos e narrativos diversos, o horror perpetrado pelos nazistas, mas não trata com profundidade as razões pelas quais Hitler e seus seguidores instituíram e levaram a efeito a Solução Final da Questão Judaica, nem todo o processo de desenvolvimento da máquina nazista.

Mas, será possível explicar a uma criança ou a um adolescente o que permanece parcialmente inexplicável? Como fazer uma criança compreender que os nazistas reuniram todo seu conhecimento, recursos e esforços para buscar e matar milhões de pessoas, incluindo crianças e idosos, simplesmente por serem judeus? A autora e mãe, partindo de seu conhecimento, experiência e pesquisa, oferece a Mathilde aquilo que a historiografia, até então, conseguiu desvendar por meio de documentos e teste-

4 A edição brasileira apresenta 55 notas para explicar alguns termos que aparecem no texto.

5 Dentre os filmes mais conhecidos do público geral estão A lista de Schindler (Steven Spielberg, 1993), A vida é bela (Roberto Benigni, 1997), O menino do pijama listrado (Mark Herman, 2008) e A escolha de Sofia (Alan J. Pakula, 1982), O pianista (Roman Polanski, 2002), O corajoso coração de Irena Sendler (John Kent Harrison, 2009). Vale lembrar que parte dessa produção filmográfica é adaptada da literatura. 
munhos. Apesar de sua centralidade nos estudos sobre o Holocausto, o testemunho de sobreviventes pertence a uma zona de neblina em que arquiteturas do horror são construídas e reconstruídas com imprecisão, ainda há algo de misterioso e enigmático em tudo isso, algo a ser desvendado, questões que talvez não tenham resposta. Para Primo Levi (2004), o testemunho se encontra numa permanente zona de tensão e impossibilidade, num paradoxo, pois os únicos aptos a darem testemunho do horror e da morte nos campos de concentração seriam aqueles que sucumbiram e que, portanto, já não podem mais testemunhar. No caso de Mathilde, a representação da pesquisa histórica se une à imaginação da criança que, por sua vez, construiu sua mitologia particular sobre Auschwitz, calcada na observação do trabalho da mãe, figura pública reconhecida na França e referência nos estudos sobre o tema, nas conversas domésticas sobre parentes assassinados ou desaparecidos, na tratativa dada ao tema pela escola, no cinema e na literatura.

E quais seriam, então, essas questões levantadas por uma menina de treze anos sobre o genocídio de um povo? Como elas surgem? Na Introdução, a autora nos revela que durante as férias de verão encontrou uma amiga, Berthe, na praia. Ela havia sido deportada para Auschwitz-Birkenau durante a guerra e a autora havia coletado seu testemunho havia 10 anos. Berthe e Wieviorka eram próximas e se falavam com frequência.

\footnotetext{
Minha filha, Mathilde, que já tinha treze anos, conhecia Berthe e não ignorava que ela estivera em Auschwitz. Sempre que eu me ausentava, elas se falavam por telefone. Mas, naquele verão, ela ficou chocada ao ver um número no antebraço esquerdo de Berthe, tatuado com tinta azul meio desbotada. De forma brutal, tudo o que se falava em casa, na televisão, nos filmes ou na escola, encarnou-se e tornou-se mais verdadeiro (WIEVIORKA, 2000, p. 5).
}

Além da questão da tatuagem de Berthe, prova material e incontestável dos crimes cometidos durante a guerra, recentemente Mathilde tivera de montar sua árvore genealógica na escola e, apesar de ter conhecido os avós paternos e maternos, teve dificuldade em precisar data e local de falecimento de três dos seus bisavós, assassinados em Auschwitz, de uma bisavó materna, que havia morrido na grande 
detenção do Velódromo de Inverno na França ${ }^{6}$, em 1942, e de tios e tias assassinados nesse mesmo período. A história que Mathilde (e a própria autora) tentava compreender era a mesma que causava tanto sofrimento a sua família e, por isso, não era e não podia ser ignorada por ela.

O que chocou a autora foi que as perguntas levantadas por Mathilde, de forma direta e crua, eram as mesmas que ela sempre fizera a si mesma e que ocuparam e ocupam a mente e os esforços de historiadores e filósofos, ou seja, questões profundas e difíceis de serem respondidas. É um olhar pela fechadura da porta, sem saber direito o que vai se encontrar do outro lado. Essa atitude curiosa, imaginativa e destemida caracteriza as perguntas realizadas por Mathilde à sua mãe. Uma forma de acesso a um outro mundo (que infelizmente continua sendo o nosso mundo!), possível apenas pelas vias da pesquisa histórica, do testemunho e da imaginação. ${ }^{7}$

Particularmente, acredito que as crianças e os jovens estejam mais aptos do que os adultos a questionar temáticas difíceis: "Por que era preciso guardar segredo, se todos os judeus do campo iriam morrer mesmo?"; "Como os homens podiam fazer isso com as crianças?”; "Os que faziam essas coisas não se sentiam culpados, não tinham remorsos?"; "Você me falou das pessoas comuns que ajudaram os judeus. Mas as grandes potências não fizeram nada?"; "Então o que os judeus fizeram para que todos quisessem matá-los?" - pergunta Mathilde à sua mãe. Por essas e outras perguntas, realizadas com sinceridade por uma jovem de treze anos, buscando compreender sua história pessoal e, ao mesmo tempo, o mundo que a cerca, é que o livro

6 Para mais informações sobre a morte em massa de judeus franceses no Velódromo de Inverno, ver A chave de Sara (Giles Paquet-Brenner, 2010).

7 "Do mesmo modo, tudo o que aqui registrei - todas essas paisagens, toda esta mitologia particular, esta Metrópole, Auschwitz -, este Auschwitz registrado aqui, que aqui fala a partir das minhas palavras, é a única entrada e saída - uma saída, talvez, ou um desfecho -, a única que existe só para mim. Suponho que isso significa que não posso entrar naquele lugar de nenhum outro modo, por nenhuma outra porta. Será que outros conseguirão entrar pela porta que aqui abri, que permanece aberta para mim?” KULKA, Otto Dov. Paisagens da Metrópole da Morte: reflexões sobre a memória e a imaginação. São Paulo: Companhia das Letras, 2014, p. 107. Otto Dov Kulka, historiador israelense, sobrevivente dos campos de Terezín e Auschwitz. 
de Annette Wieviorka lança luz em questões históricas, éticas, filosóficas e humanas essenciais, que não podem e não devem ser colocadas de lado, e que não passaram despercebidas ao olhar atento de uma criança. 


\section{REFERÊNCIAS}

KULKA, Otto Dov. Paisagens da Metrópole da Morte: reflexões sobre a memória e a imaginação. Tradução Laura Teixeira Motta. São Paulo: Companhia das Letras, 2014.

LEVI, Primo. Os afogados e os sobreviventes: os delitos, os castigos, as penas e as impunidades. Tradução Luiz Sérgio Henriques. São Paulo: Paz e Terra, 2004.

SELIGMANN-SILVA, Márcio O. Memória, História e Literatura: o testemunho na era das catástrofes. Campinas: Editora UNICAMP, 2003.

WIEVIORKA, Annette. Auschwitz explicado à minha filha. Tradução Maria Beatriz de Medina. São Paulo: Via Lettera Editora, 2000.

WIEVIORKA, Annette. Encyclopedia.com, 2020. Disponível em https://www.encyclopedia.com/religion/encyclopedias-almanacs-transcripts-and-maps/wieviorka-annette. Acesso em: 4 de dez. 2020. 